analytic therapy" without being explicit that these were agreed quality standards to be present in any practice of CAT. Furthermore, there seemed to be no agreed level of expertise expected of the therapists; however, the impression was given that implicit standards and practice were operating.

The link between supervision, (as would be practised in the normal course of good psychotherapy), and audit was not clarified. We were therefore left wondering if the analysis of audio tapes was routinely used as part of supervision or whether it has been introduced sporadically and specifically for the purpose of audit. No comment was made about the potential difficulties in audio taping therapy sessions, and its effect on the process of therapy.

We felt that this paper raised more questions than it answered. Our recommendation would be that it could have been more valuable as a descriptive account of the process of setting up this kind of audit of psychotherapy, acknowledging its limitations and difficulties, rather than the quasiscientific inquiry it became.

MEg KERR, J. BIRTLE, F. ROLDAN, J. APPLEFORD, J. Evans, R. SARgEant, C. KENWOOD, J. RAMSDALE and L. CHESTER, Uffculme Clinic, Queensbridge Road, Moseley, Birmingham B13 8QD

Sir: On criticising my work Kerr et al raise issues of considerable importance in psychotherapy research. They take exception to what they see as subjective and evaluative judgments made in my audit, and presented in a "quasiscientific" format, citing for example, the use of the term "definitive interpretations". This is odd as the term "definite" interpretations is closely defined (point 1 in Table 1). They also criticise a comment about "communicative misfires" even though this is clearly signposted as an impression.

The suggestion that clinical material should have been presented was prevented by space constraints although this would not guarantee greater objectivity because of biasing effects of selection, recall and description. Taping could eliminate some bias but Kerr et al have reservations about the effects of taping on therapy and take me to task for falling to discuss this. The matter does need discussion, most importantly in the area of ethical and practical criteria for gaining informed consent to taping in a way which respects psychodynamic and power issues. But in my experience the chief anxieties, problems and resistances to taping arise in the therapists not the patients.

I was sad my paper might have given the impression that supervision was not a regular, mandatory part of the practice of CAT and that the authors implied that the therapy done at Guy's was not good. Neither is true.

I was astonished that Kerr et al felt it a criticism that my paper raised more questions than it answered. I take this as an (unintended) compliment. The chief point of my paper was to report how (more by luck than by judgement) an audit I had done which had certain features did change practice (whether for the better remains to be evaluated). I suggested that success in this respect resulted from how our evaluations managed to be both close to and distant from the concerns of clinicians and supervisors. If this feature made for "quasiscience" then at least in audit terms it seems to have worked.

F. Denman, 24 Lawrence Street, Chelsea, London SW3 $5 N F$

\section{The same old scene?}

Sir: Lewis (1991) states having a publication (and not simply being involved in some research project) is important in getting to interview. Postmembership appears to be the optimum time for this as examinations no longer loom on the horizon.

Most books on research regard the process as starting with the formation of new hypotheses and then the subsequent generation of methods to test them. Flanigan (1992) showed that 14.9\% of papers in the British Journal of Psychiatry had a junior author. This included the senior registrar grade. Lewis was concerned with the progression of registrars to the senior registrar grade. For registrars the situation is still poor: (excluding non-UK authors) there were 258 authors present in the January to June 1993 issues of the Journal. Of these $17(6.5 \%)$ were registrars, and were almost (bar one) exclusively present in original papers (7 out of $158-4.4 \%$ ) and brief reports (9 out of $44-20.4 \%$ ). There were no papers of original research with sole authorship.

The trend is therefore unchanged for registrars. Since brief reports continue to be the only realistic, but still sparse, method of obtaining publication it shows that publication does not equate with research. If Lewis' hypothesis still holds then the determining factor for interview is not the generation of new hypotheses and testing them (pure research), nor really the testing of other professionals' ideas (passive research normally involving the laborious administration of innumerable rating scales), but is actually dependent on which patients you see. Essentially career progression is determined, not by having experience of seeing thousands of mentally ill and learning to manage them, but more by the one case of an Eskimo 
with concurrent Capgras and koro we all pray will turn up!

LEWrs. S. (1991) The right stuff? A prospective controlled trial of trainees' research. Psychiatric Bulletin. 16, 478480.

Flanigan, P. (1992) Junior publications in the British Journal of Psychiatry. Psychiatric Bulletin, 16, 518.

ANDREW SMITH, West London Healthcare NHS Trust, Uxbridge Road, Southall, Middlesex UB1 3EU

\section{Criteria for compulsory hospital admission}

Sir: I am puzzled by J. H. M. Crichton's article on the revised Code of Practice for the Mental Health Act, 1983 (Psychiatric Bulletin, January 1994, 18, 45-46). He says that Chapter 2 about assessment and admission specifies "that a patient may be admitted because of danger to others even without danger to the patient's own health and safety".

This is nothing new. What is new is the point underlined by Ministers in the Foreword to the Code, that risks to their own or other people's safety are not the only criteria for patients' admission, and that they may be detained in the interests of their own health, OR safety, OR for the protection of others. Only one of these grounds needs to be satisfied.

Members of the National Schizophrenia Fellowship have been concerned for a long time that some psychiatrists do not appear to know what the criterla for compulsory admission are. It is very disappointing that an article devoted to the revised Code does not pick up the change of wording specially introduced to clarify this point.

DOROTHY SILBERSTON, Vice-Chairman, National Schizophrenia Fellowship, 28 Castle Street, Kingston-upon-Thames, Surrey KT1 1SS

Sir: I am grateful to Dorothy Silberston for raising an important point about the Department of Health's new guidance on the use of the criteria for compulsory hospital admissions.

It was not implied, however, in the paper on the revised Code of Practice that there was any change in the criteria for compulsory admission. which would of course require change in statute law. It is clear from the references in the paper that it was based on the Code of Practice laid before Parliament on the 19 May 1993; it was written and submitted before the Code was published. There was no opportunity to comment on the Secretary of State's foreword which was not included in the Parliamentary copy.

I think Dorothy Silberston is mistaken in her view that psychiatrists do not know the criteria for compulsory admission. The conclusion of the paper comments on this point. It is clear that the criteria for admission have been more clearly 'spelt out' not only in the revised code but in its foreword and in press releases from the Department of Health. The purpose of this new emphasis I think is less about informing psychiatrists about admission criteria and more about persuading psychiatrists to lower their threshold when considering if a patient fulfils compulsory admission criteria. This point is further elaborated in a paper soon to be published (Crichton, 1994).

CRICHTON, J.H.M. (1994) Supervised discharge. Accepted Medicine Sctence and the Law.

JOHN H. M. CRICHTON, University of Cambridge, Institute of Criminology, 7 West Road, Cambridge CB3 9DT

\section{Continuing medical education}

Sir: May I extend the comments on continuing medical education (Sensky, Psychiatric Bulletin, January 1994, 18, 18-21, and Ferrier \& Cooper, Psychiatric Bulletin, January 1994, 18, 43-44).

Continuing medical education for consultants and non-trainee psychiatrists should include regular reviews of developments in the other branches of medicine and surgery. Could the College consider commissioning general review lectures of recent developments in various medical disciplines for the Annual Meeting?

D. M. HAMBIDGE, Royal Air Force Outpatients Department, Nocton Hall, Nocton, Lincoln LN4 2AA

Sir: I agree with the thrust of Dr Hambidge's letter although I would need some convincing about the reevance of surgery. I think a better format for this than large review lectures during College meetings would be:

(a) update one day courses for a maximum of 30 consultants on the topic, endocrinology and psychiatry

(b) articles on the same type of topics in the new College Journal for "continuing professional development of consultants, Advances in Psychiatric Treatment'. We will plan to act on this.

A. C. P. SIMS, Chairman, Committee on Continuing Medical Education, Royal College of Psychiatrists

\section{Label of personality disorder}

Sir: I was disappointed with the letters in response to Dr Steadman's article (Psychiatric 